\title{
Membrane Operations for Process Intensification in Desalination
}

\author{
Enrico Drioli $1,2,3,4$, Aamer Ali ${ }^{1, *}$ and Francesca Macedonio ${ }^{1,2, *}$ \\ 1 Institute on Membrane Technology (ITM-CNR), National Research Council, c/o The University of Calabria, \\ Cubo 17C, Via Pietro Bucci, Rende 87036, Italy; e.drioli@itm.cnr.it \\ 2 Department of Environmental and Chemical Engineering, University of Calabria, Rende 87036, Italy \\ 3 WCU Energy Engineering Department, Hanyang University, Seoul 133-791, Korea \\ 4 Center of Excellence in Desalination Technology, King Abdulaziz University, Jeddah 21589, Saudi Arabia \\ * Correspondence: amir_hmmad@hotmail.com (A.A.); francesca.macedonio@unical.it or \\ f.macedonio@itm.cnr.it (F.M.); Tel.: +39-0984-492014 (A.A.); +39-0984-492012 (F.M.)
}

Academic Editor: Mohamed Khayet

Received: 16 December 2016; Accepted: 13 January 2017; Published: 20 January 2017

\begin{abstract}
Process intensification strategy (PIS) is emerging as an interesting guideline to revolutionize process industry in terms of improved efficiency and sustainability. Membrane engineering has appeared as a strong candidate to implement PIS. The most significant progress has been observed in desalination where substantial reduction in overall energy demand, environmental footprint, and process hazards has already been accomplished. Recent developments in membrane engineering are shaping the desalination industry into raw materials and energy production where fresh water will be produced as a byproduct. The present study discusses the current and perspective role of membrane engineering in achieving the objectives of PIS in the field of desalination.
\end{abstract}

Keywords: process engineering; membrane operations; desalination; metrics

\section{Introduction}

During the last 50 years, the world's population has doubled and gross domestic production has increased ten folds, reflecting the underlying massive industrialization during this period. These developments have put the resources of freshwater, energy, and raw materials under ever-growing strain. Energy consumption has increased by five times during the last five decades and the majority of this energy consumption is coming from finite and polluting fossil fuels [1]. In the water sector, it has been estimated that two thirds of the world's population might be facing insufficient access to clean freshwater by 2025 [2]. Similarly, traditional mining is facing several environmental and sustainability related concerns. The scenario places an emphasis on sustainable industrial growth across the globe that can be realized by using the material and energy resources more efficiently and by exploiting the nontraditional but sustainable resources of these commodities while, at the same time, eliminating or minimizing the environmental hazards associated with the related processes [3]. These requirements clearly point out the urgency to develop new processes capable of producing and using energy, freshwater, and raw materials more efficiently and with the potential to exploit alternative resources of these products.

Lack of a precise definition of sustainable development has resulted in the evolution of specific guidelines such as the PIS to implement the concept of sustainable development. Process intensification as defined by Stankiewicz and Moulijn [3,4] is the development of novel equipment and techniques that, compared to those commonly used, dramatically improve manufacturing and processing by decreasing substantially equipment size, improving raw material to production ratio, decreasing energy consumption and waste production, and that ultimately results in cheaper, efficient, safer, and more 
sustainable technologies. Modern membrane engineering represents one of the most interesting ways for developing processes in accordance with the guidelines provided by PIS to meet the challenges of the modern world $[5,6]$. The main features of membrane engineering which make it perfectly aligned with PIS include its high selectivity and permeability for transport of specific components, the ease with which it can integrate with other processes or other membrane operations, its tendency to be less energy intensive and highly efficient, as well as its tendency to have low capital costs, small footprints, and high safety, operational simplicity, and flexibility [5,7-9]. These exceptional features extend the sphere of applications of membrane engineering from water, energy, and raw materials sectors to sophisticated biomedical applications.

Desalination represents one of the industrial sectors where membrane engineering has emerged as the key player to successfully implement the concept of PIS. In many parts of the world, conventional thermal desalination plants have been replaced with far less energy intensive, compact, and safer reverse osmosis (RO) units. Currently $\mathrm{RO}$ occupies more than a $60 \%$ share of the desalination market [10]. Thermal processes are limited only to the regions with abundant sources of fossil fuels, such as the Middle East. However, despite their loudly spoken advantages, the pressure driven processes face some challenges that hinder their wide spread and uniform growth in water stressed regions across the globe: operation at high pressure, high energy consumption, utilization of high grade energy, limited recovery factor (typically $40 \%-50 \%$ ), and disposal of brine are the most significant obstacles that negatively affect the process economy and cause environmental problems. Several investigations have been carried out to tackle these challenges. These investigations have focused on improving the process performance of $\mathrm{RO}$ by optimizing the operating conditions and process design, by introducing a better control system, and by integrating the process with renewable energy resources. In order to optimize the process, the impact of energy recovery devices, membrane permeability, process configuration, brine management cost, pump efficiency, and frictional pressure drop on specific water cost under the constraints imposed by the osmotic pressure has been analyzed [11]. In another study, it was concluded that further reduction in specific water cost in $\mathrm{RO}$ is less likely to take place through the development of more permeable membranes, rather it should come from better fouling and scaling control, improved brine management, lower pretreatment cost, improved process control, and process optimization [12]. Improved control systems have been developed to incorporate the variation in feed water salinity, large set-point changes, and for the optimum management and operation of integrated wind-solar energy generation and $\mathrm{RO}$ desalination systems [12-14].

In addition to the abovementioned approaches, the use of new membrane operations offer promising solutions to these challenges. The use of the new processes in combination with the traditional ones can not only resolve the problem of waste handling but can also provide the opportunity to boost the economy of the process. An integrated approach takes into account energy savings (also production in certain cases), water rationalization, minimization of chemical utilization, resource recovery, and waste production [4]. Therefore, integrated systems can contribute significantly to the solution of strategic aspects of industrial productions. Different membrane operations can be coupled in integrated systems in order to approach the ambitious objective of "zero liquid discharge". A qualitative comparative analysis of various generations of desalination technology on the basis of different process intensification parameters has been explained in Figure 1. The first generation desalination plants (thermal) are bulky, consume huge amounts of energy, and have large environmental impacts in terms of carbon emissions and the use of various chemicals (e.g., anti-sealants). Due to high temperatures, the safety level of these plants is relatively weak. With the advent of RO technology, the situation has improved. However, energy consumption and environmental impact (in terms of carbon emission and brine disposal) of RO is still high. These drawbacks can be addressed by integrating novel membrane processes including pressure retarded osmosis (PRO), membrane distillation (MD), forward osmosis (FO), and reverse electrodialysis (RED). The details of these new processes have been explained in later sections. 


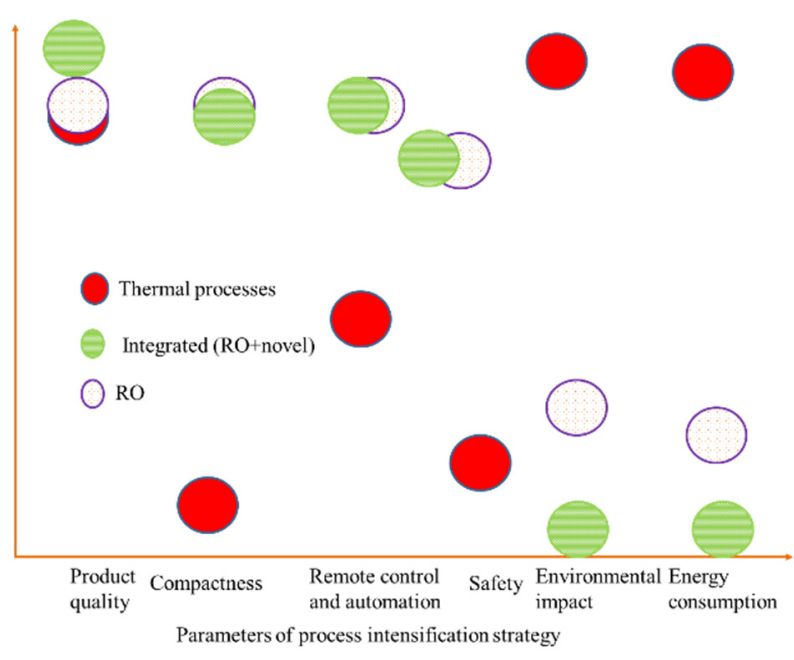

Figure 1. Qualitative analysis of conventional thermal, reverse osmosis (RO), and integrated membrane processes for desalination based on various parameters of PIS (process intensification strategy). $y$-axis indicates the qualitative comparison of the parameters list along $x$-axis for different processes (thermal, integrated, RO alone).

\section{New Metrics for PIS (Process Intensification Strategy)}

For an easy and fair comparison of conventional unit operations with membrane technology, Criscuoli and Drioli [15] have proposed some new metrics. The metrics allow for the monitoring of the progress and improvement of membrane operations in the logic of process intensification taking into account plant size, weight, flexibility, modularity, etc. Overall assessment of sustainable processes should also consider existing metrics (mass and waste intensity), environmental factors, economic, and society indicators. Mass and waste intensities (Equations (1) and (2), respectively) are used to quantify the amount of product which is produced from a particular process with respect to the amount of input materials or waste produced from the process. Reduction in mass and waste intensities is the preferred form of improvement of the process. Membrane operations have small footprints and, therefore, can be used to quantify how productivity is influenced by plant size or weight (Equations (3) and (4), respectively). The productivity to weight ratio is of particular interest if the plant is constructed off-shore or in remote areas. Taking into account the entire lifetime of the plant, it is important that it has flexibility and modularity (quantified by Equations (5) and (6), respectively), so it can be adjusted according to changes in the productivity, variation in pressure, temperature, feed compositions, or other process related parameters. The modularity equation considers changes (increase/decrease) in plant size compared to the productivity. These metrics should also be higher than 1 for a membrane plant to be preferred [15].

$$
\begin{aligned}
\text { Mass Intensity } & =\frac{\text { Total mass }[\mathrm{kg}]}{\text { Mass of product }[\mathrm{kg}]} \\
\text { Waste Intensity } & =\frac{\text { Total waste }[\mathrm{kg}]}{\text { Mass of product }[\mathrm{kg}]} \\
\text { Productivity } / \text { Size ratio } & =\frac{\frac{\text { Productivity }}{\text { Size }}(\text { Membranes })}{\frac{\text { Productivity }}{\text { Size }}(\text { Tradional process })}
\end{aligned}
$$




$$
\begin{aligned}
& \text { Productivity } / \text { Weight ratio }=\frac{\frac{\text { Productivity }}{\text { Weight }}(\text { Membranes })}{\frac{\text { Productivity }}{\text { Weight }}(\text { Tradional process })} \\
& \text { Flexibility }=\frac{\text { Variations }_{\text {handled }}(\text { Membranes })}{\text { Variations }} \\
& \text { Modularity }=\frac{\left.\left|\frac{\text { area }_{2}}{\text { area }_{1}}-\frac{\text { productivity }_{2}}{\text { productivity }_{1}}\right| \text { (Membranes }\right)}{\left|\frac{\text { area }_{2}}{\text { area }_{1}}-\frac{\text { productivity }_{2}}{\text { productivity }_{1}}\right|(\text { Tradional process })}
\end{aligned}
$$

\section{New Membrane Operations Aligned with PIS}

\subsection{Membrane Distillation/Crystallization}

Besides the widely accepted $\mathrm{RO}$ in desalination which has already outclassed traditional thermal processes, new and relatively less explored membrane operations with more promises are emerging. In the desalination industry, membrane distillation and membrane crystallization, in particular, can add a positive effect on the process by increasing the overall water production and recovering valuable salts from the brine, thus approaching zero-liquid-discharge and the goals of process intensification strategy. The recovery of minerals from brine through the use of membrane distillation/crystallization might have a significant role in determining the future outlook of the mining industry. While the mining industry is under extreme stress due to excessive exploitation of minerals, the volume of brine (and therefore minerals contained in it) is increasing across the globe due to increases in the net volume desalination capacity. Seawater brine contains a number of essential as well strategic elements including sodium, magnesium, barium, lithium, etc. and can thus serve as a form of open sky mine for the recovery of these components. Dramatic increases in the consumption of some of these materials have been observed recently. For example, the use of strontium has increased in the oil and gas industry as weighing material in mud. Similarly, traditional sources of lithium might not be enough in the near future to fulfil its requirements in the electronic industry (especially considering hybrid vehicles). Sea-mining offers a potential solution to the problem of mineral depletion. A comparison of potentially recoverable minerals from the brine of existing desalination plants and their current exploitation through conventional mining has been illustrated in Figure 2 [16]. It can be noted from the figure that the amount of $\mathrm{Na}$ and $\mathrm{Mg}$ in brine from current desalination capacities is more than that obtained through conventional mining. Similarly, strontium and lithium are both found considerable quantities in brine, indicating an attractive opportunity for the recovery of these minerals from the brine. The situation will further improve on the completion of contracted and planned desalination capacities across the globe.

In 2002, Drioli and co-workers [17] suggested for the first time membrane crystallizers for seawater desalination in an integrated approach with RO. In this study real seawater from the Tirrenian coast was first treated by nanofiltration (NF) and RO followed by membrane crystallization (MCr) treatment of the $\mathrm{RO}$ concentrate with the production of $\mathrm{NaCl}$ [17]. The prospect of introducing $\mathrm{MCr}$ to $\mathrm{RO}$ brine has the potential to increase the fresh water recovery factor from around $50 \%$ to above $90 \%$ in combination with salts recovery. In fact, one of the main advantages of $\mathrm{MCr}$ is that it does not suffer from osmotic phenomena like $\mathrm{RO}$ because the driving force is a temperature gradient instead of a pressure gradient. Therefore, $\mathrm{MCr}$ can treat highly concentrated and even saturated solutions without any particular reduction in driving force and, as a consequence, in trans-membrane flux. The hydrophobic character of the membrane provides a complete rejection of non-volatiles, thus producing water at very high qualities. Moreover, the low used temperatures (normally in the range of $40-80^{\circ} \mathrm{C}$ ) permit the use of waste grade heat or other renewable energy sources. In the subsequent years of this first study, several research activities have focused on integrated membrane systems in desalination. In 2004, a MCr unit was applied on a synthetic NF retentate. That resulted in the recovery of $\mathrm{NaCl}$ and magnesium sulfate in 
the form of Epsomite $\left(\mathrm{MgSO}_{4} \cdot 7 \mathrm{H}_{2} \mathrm{O}\right)$ [18], a hydrated form of magnesium sulphate of great economic value. Another great advantage of membrane crystallizer is, in fact, the possibility to obtain different polymorphs and forms (hydrous or anhydrous) by simply tuning the operative conditions [19,20]. Effectively, in a MCr the membrane matrix acts as a selective gate for solvent evaporation, modulating the final degree and the rate for the generation of the supersaturation. Hence, the possibility to act on the trans-membrane flow rate, by changing the driving force of the process, allows for the potential to modulate the final properties of the crystals produced both in terms of structure (polymorphism) and morphology (habit, shape, size, and size distribution). Moreover, the possibility to separate the solvent evaporation (occurring inside the membrane module where the flowing solution is below the supersaturation condition) and the crystallization stage (performed in a separate tank on the retentate line operating in the metastable regime of supersaturation) allows for the proper control of the crystallization temperature, thus addressing the formation of a particular form (hydrous or anhydrous).

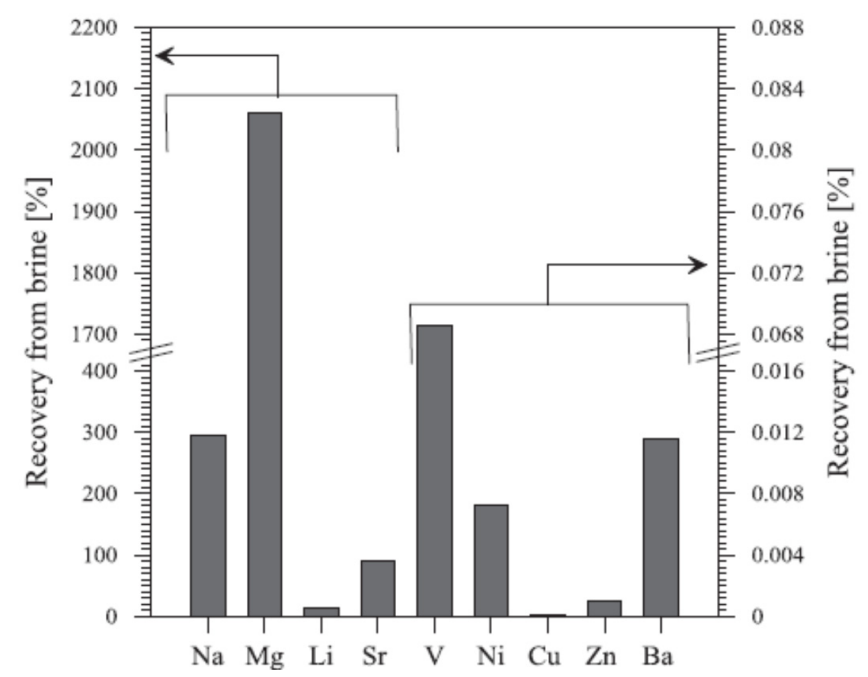

Figure 2. A comparative analysis of potentially recoverable minerals from brine in percentage with respect to their quantity obtained through traditional mining.

The European funded project: Membrane Based Desalination: An Integrated Approach (MEDINA) was launched in 2006. This project focused on integrated membrane systems for improving the efficiency of desalination. Integrated systems consisting of microfiltration (MF), NF, and RO with a membrane crystallizer coupled to NF and RO can achieve a water recovery factor as high as $92.4 \%$, thus approaching zero liquid discharge and recovery of valuable raw materials [21]. Integration can be achieved in several configurations, as mentioned in [22-24]. Integrated membrane systems are also very interesting from an economical point of view. The specific water cost apparently increases when MD or $\mathrm{MCr}$ are introduced (Figure 3), mainly due to the requirement of steam when operating the thermal processes with respect to electrical energy demand in pressure driven membrane operations [24]. Nevertheless, the water recovery factor increases significantly with the introduction of MD and $\mathrm{MCr}$ from only $40 \%$ in $\mathrm{RO}$ (configuration 1) to above 90\% for integrated operations (configuration 7). However, if the sale of $\mathrm{CaCO}_{3}, \mathrm{MgSO}_{4} \cdot 7 \mathrm{H}_{2} \mathrm{O}$, and $\mathrm{NaCl}$ is considered the water production cost can be negative (solid lines shown in Figure 3) [24]. In this case, the desalinated fresh water can just be a by-product of mineral production. In addition to RO brine, other industrial saline water streams can also be considered for recovery of contained minerals.

Several developments are due for widespread applications of membrane distillation/crystallization process. The biggest issue is the unavailability of specific membranes with the required hydrophobicity, porosity, pore size distribution, and antifouling/wetting character. From a phenomenological point of view, a better understanding and control of temperature polarization is required. Research efforts are also required to improve the module design and to develop better logics for energy recovery. There is 
a need to develop large scale prototypes to assess the true techno-economic potential of the process and to comprehend the unforeseeable problems.

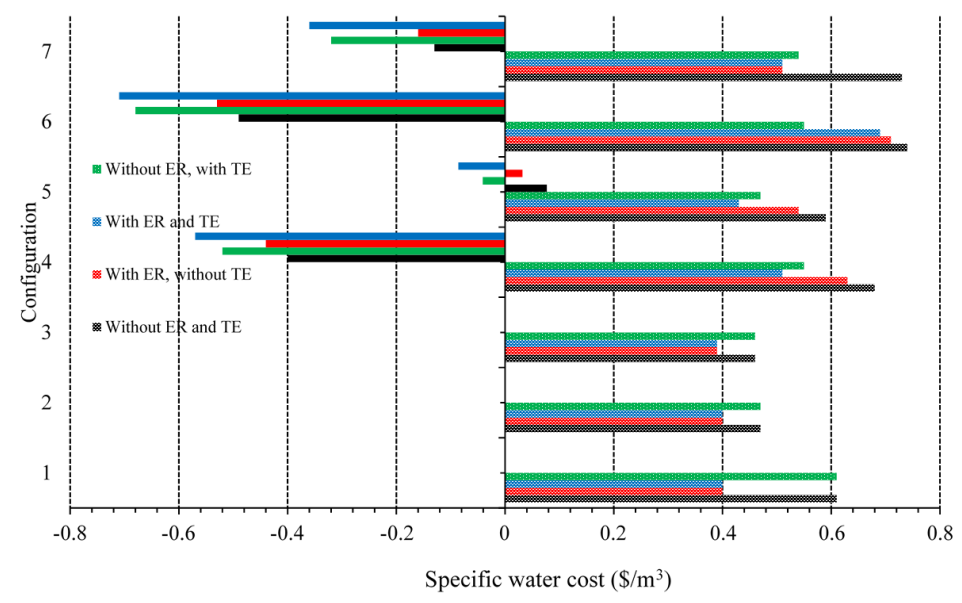

Figure 3. Specific water cost of different integrated configurations without considering sale of salt (patterned bars) and after considering sale of salt (solid lines). ER: Mechanical energy recovery; TE: Thermal energy recovery; MF, Microfiltration; NF, Nanofiltration; MD, membrane distillation; 1 = Configuration 1: RO alone; 2 = Configuration 2: NF-RO; 3 = Configuration 3: MF-NF-RO; 4 = Configuration 4: MF-NF(-MCr)-RO; 5 = Configuration 5: MF-NF-RO(-MCr); 6 = Configuration 6 : MF-NF(-MCr)-RO(-MD); 7 = Configuration 7: MF-NF(-MCr)-RO(-MCr).

\subsection{Energy Production in Desalination Sector}

New developments and progresses in membrane engineering are creating exciting opportunities to generate renewable and sustainable energy in the desalination sector. This can be achieved by mixing two streams with different salinity gradients. The power generated is termed as blue energy or salinity gradient power. The total global potential of blue energy has been estimated to be about 1.4-2.6 TW out of which $\sim 980 \mathrm{GW}$ is extractable depending on the technology applied [25]. It has been demonstrated that salinity gradient energy is able to fulfil $20 \%$ of the current global energy demand. This can impart a significant contribution in lowering the dependence on carbon based energy production. PRO and RED are two of the most interesting membrane operations to harness this energy. Integration of these operations with conventional and emerging desalination operations produces synergetic effects. Besides reducing the net energy consumption of desalination processes, these operations also make desalination more clean and green by producing electricity with zero carbon emission and by diluting the concentrated brine which otherwise is a nuisance. By combining PRO or RED with membrane-based desalination systems like RO and MD, a synergetic advantage of both systems can be obtained in the logic of process intensification.

\subsubsection{Reverse Electrodialysis (RED)}

In hybrid RED-membrane desalination systems, highly concentrated reject brine (from both thermal and membrane desalination plants) is used for energy recovery. The generated electricity can be used to fulfill (partly or entirely) energy requirements of desalination system. Various integrations of RED with RO are possible [18]. RED can serve as a pretreatment, post treatment, or both steps for RO. Depending upon the configuration applied, RED can serve as energy reducer to the net energy generator in an RO desalination plant [18]. Similarly, integration of RED with MD can give synergetic effects. Application of MD at RO retentate can increase recovery factor while RED connected at retentate of MD can produce electricity while simultaneously decreasing its concentration.

Recently, Tufa et al. experimentally evaluated the integrated application of RED and MD for clean water and energy generation [22]. The conceptual illustration of the investigated hybrid system 
is presented in Figure 4. In particular, MD was operated with seawater $\mathrm{RO}$ retentate $(1 \mathrm{M} \mathrm{NaCl})$. Brine with concentrations of up to $5.4 \mathrm{M}$ of $\mathrm{NaCl}$ (near supersaturation) was obtained from direct contact membrane distillation (DCMD) operated on $\mathrm{RO}$ brine $(1 \mathrm{M} \mathrm{NaCl})$ at a feed recirculation time of $20 \mathrm{~h}$ and a temperature gradient of $30^{\circ} \mathrm{C}$ [15]. The DCMD brine was then used for energy recovery by RED system. The level of output power of RED depends on feed (MD brine) concentration and operating parameters like temperature and flow rate. For example, the maximum power density of a RED system was observed to increase from $0.9 \mathrm{~W} / \mathrm{m}^{2}$ to $2.4 \mathrm{~W} / \mathrm{m}^{2}$ when the MD brine concentration was increased from $4 \mathrm{M} \mathrm{NaCl}$ to $5.4 \mathrm{M} \mathrm{NaCl}$, respectively [15]. The output power from the RED was also observed to increase with temperature $\left(0.027 \mathrm{~W} /{ }^{\circ} \mathrm{C}\right.$ on average) and flow velocity, which can be optimized to set appropriate working conditions for improved system performance. In general, energy recovery from DCMD brine by RED enables the supply of extra energy required for desalination. This represents a promising strategy towards low energy desalination and Near-Zero Liquid Discharge.

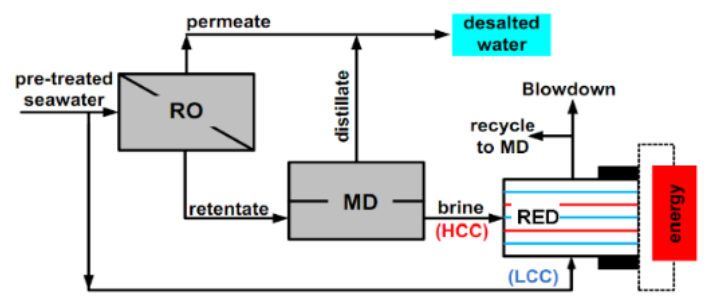

Figure 4. Integrated application of MD with RO and RED (reverse electrodialysis) for water and energy production [26]. HCC and LCC represent High Concentration Compartment and Low Concentration Compartment of the RED cell, respectively.

The feasibility of an integrated MD-RED depends on several factors affecting the performance of individual system units. Different strategies can be followed to improve the performance of the system in terms of water production capability, output power, and energy efficiency. The energy consumption in $\mathrm{RO}$ or MD can be reduced by controlling the operating conditions, using appropriate pre-treatment techniques, and designing optimal membranes and modules $[12,21]$. The potential and hence the output power from a RED unit can be improved by the development and use of highly permeable and low resistance IEMs (ion exchange membranes) [11]. Besides the benefit obtained at higher temperatures for both systems (MD and RED), the coupled system enables the possibility to use and convert waste heat to electricity.

\subsubsection{Pressure Retarded Osmosis (PRO)}

$\mathrm{PRO}$ is one of the most interesting membrane processes to harness clean energy from a salinity gradient. In PRO, a semipermeable membrane is applied to separate high and low salinity solutions. The osmotic pressure extracts the fresh water from dilute to the concentrated solution. The pressure generated on the high salinity solution side can be used to run a hydro turbine $[27,28]$. For this process, several combinations of feed and draw solutions have been tested including river and seawater [29], seawater brine and wastewater retentate, freshwater and synthetic $\mathrm{NaCl}$ solution [30], and seawater and municipal wastewater [31].

Synergetic effects can be achieved by introducing PRO into desalination systems in terms of reduction of waste footprint of feed solution, and the dilution of the draw solution, which can reduce the energy demand of desalination system and can minimize the environmental consequences of brine disposal. Achili et al. [31] have reported experimental data on a $\mathrm{RO}$ unit getting a benefit from pressure generated by a PRO unit. The authors have also reported the power density data of PRO-RO system ranging between $1.1 \mathrm{~W} / \mathrm{m}^{2}$ to $2.3 \mathrm{~W} / \mathrm{m}^{2}$. The authors have concluded that the proposed system can bring the desalination energy demand down to $1 \mathrm{kWh} / \mathrm{m}^{3}$. In order to increase the power density of the PRO process, Han et al. [30] have proposed the integration of PRO with a closed loop 
MD process. MD maintains a high concentration of draw solution that extracts freshwater from the feed solution. The authors have claimed that the proposed system can achieve a high recovery factor, huge production of power, and minimum membrane fouling and environmental impacts.

The concept of integrating PRO with other membrane operations is also gaining attention at industrial scales. Currently, Applied Biomimetics and partners have setup two pilot plants aiming to generate electricity from geothermal wastewater by using PRO technology (energyforskining.dk/ node/8345). The proposed plan is expected to produce emission free electricity while at the same time bringing the salinity level of the geothermal brine below the permissible limits. The dilution of geothermal brine via PRO will also reduce the corrosion and scaling potential of a geothermal stream. A similar concept has been used in a Mega-ton project where a pilot plant has been constructed in Fukuoka (Japan). The plant uses $460 \mathrm{~m}^{3}$ /day of RO brine which is mixed with $420 \mathrm{~m}^{3}$ /day of wastewater. The plant has been able to achieve power density as high as $13 \mathrm{~W} / \mathrm{m}^{2}$ at 30 bar hydraulic pressure by using commercial hollow fibers from TOYOBO (Osaka, Japan).

Another pilot-scale PRO-hybrid research project is being conducted under the name "Global MVP (Membrane distillation, Valuable resource recovery, Pressure retarded osmosis) Project" in Korea (Figure 5). The objective of this project was to evaluate the feasibility of the RO-MD-PRO hybrid process in terms of reducing the discharged water concentration and the energy consumption. In the hybrid process, the concentrated RO brine enters the MD feed side, and the further concentrated MD brine is then utilized as a PRO draw solution while the waste water effluent is used as the feed solution. Consequently, an improvement in the total plant efficiency compared to a stand-alone RO plant is expected due to the additional water production by MD and the reduction of net energy consumption resulting from the PRO energy generation. Specifically, the following pilot plant will be built: a RO system capable of $1000 \mathrm{~m}^{3}$ / day water production, a MD system with a water production capacity of $400 \mathrm{~m}^{3} /$ day, and a PRO system having a $5 \mathrm{~W} / \mathrm{m}^{2}$ power density [32]. Recently Statkraft has terminated its activities on power generation through PRO. The company has been operating a prototype with $10 \mathrm{~kW}$ capacity by applying seawater and river water as draw and feed solutions, respectively, which were separated through a membrane with power density of $1 \mathrm{~W} / \mathrm{m}^{2}$, which was far less than the economical break-even point $\left(5 \mathrm{~W} / \mathrm{m}^{2}\right)$. Although membranes with power densities as high as $10 \mathrm{~W} / \mathrm{m}^{2}$ have been reported in current literature, the price and commercial availability of these membranes still remain the unanswered questions. Besides high power density, the appropriate membranes should exhibit high selectivity and minimum reverse solute diffusion. Internal concentration polarization and fouling are the other main issues hindering the performance of PRO processes. Due to exposure of the support layer to the feed solution, fouling and internal concentration polarization issues are more severe in PRO than pressure driven processes. Besides the proper treatment of feed solution, the design and modification of the support layer must be emphasized to alleviate this phenomenon.

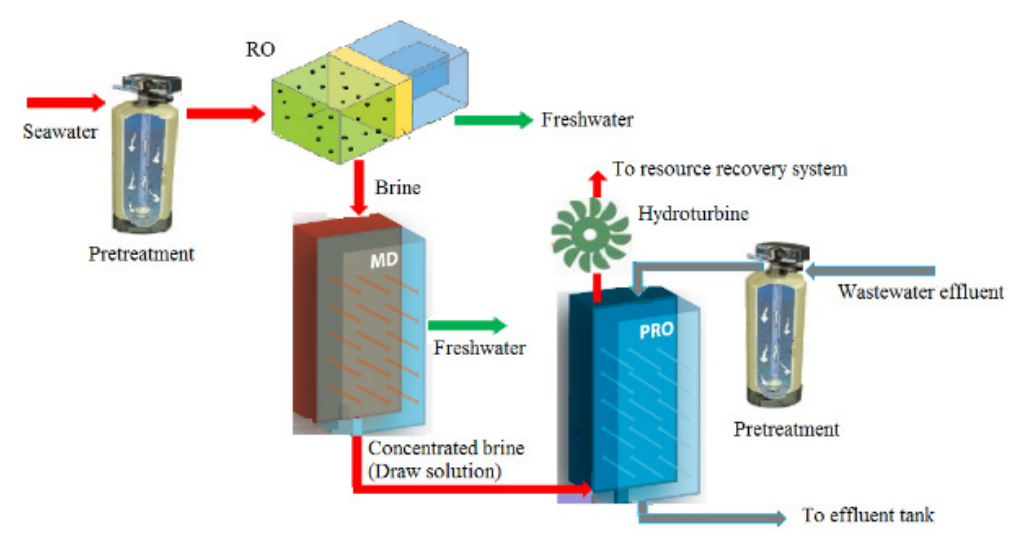

Figure 5. Schematic diagram of hybrid RO-MD-PRO in Korea implemented under Global MVP project. 


\section{Evaluation of New Metrics}

A comparison of different overall desalination processes in terms of various metrics for process intensification has been provided in Figure 6. MSF (multi-stage flash), being the most widely used thermal desalination process, has been considered as the base line and therefore the value of all the metrics for this is one. The figure indicates that various metrics show huge variations for different processes. MI (mass intensity) for $\mathrm{RO}$ and $\mathrm{MD}$ reduce greatly due to improved recovery factor (considered $50 \%$ and $86 \%$, respectively, in current study). RO shows the maximum value of productivity/weight ratio (PW) due to high membrane permeability and elimination of heavy metallic parts, which are essential components of MSF plant. This aspect is particularly important for off-shore or remote installations. It is also evident from the figure that the PW for $\mathrm{RO}$ is higher than $\mathrm{MD}$, which can be attributed toward the high flux of RO considered in the current study (Table 1). Larger membrane area requirement in case of MD implies a larger number of modules that will increase the weight, and thus PW will go down. Similarly, PS for MSF is the least, thereby indicating the large foot print of the plant. Overall, the comparison indicates that new membrane operations (MD in the current example) can be optimum candidates to overcome the drawbacks (limited MI) of conventional RO processes.

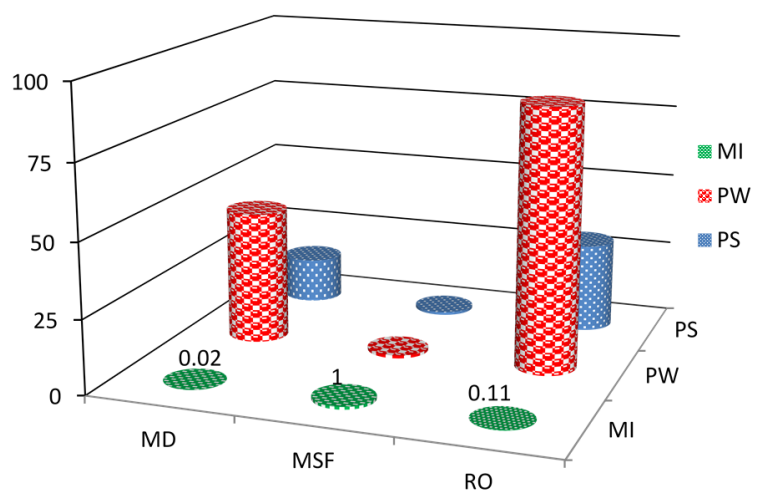

Figure 6. PI (process intensification) metrics for MD, multi stage flash (MSF), and RO. MI, mass intensity; PW, productivity/weight ratio; PS, productivity/size ratio.

Table 1. Parameters and assumption used in calculation of various PI (process intensification) metrics shown in Figure 6.

\begin{tabular}{cc}
\hline Feed solution & Seawater \\
\hline Plant capacity $\left(\mathrm{m}^{3} / \mathrm{h}\right)$ & $1250[33]$ \\
MD flux assumed $\left(\mathrm{kg} / \mathrm{m}^{2} \cdot \mathrm{h}\right)$ & 4 \\
Volume of MSF (multi stage flash) unit $\left(\mathrm{m}^{3}\right)$ & $18 \times 4 \times 3$ [33] \\
Material of construction of MSF unit & Stainless steel \\
Density of steel $\left(\mathrm{kg} / \mathrm{m}^{3}\right)$ & 8000 \\
Average permeate flow for RO $\left(\mathrm{reverse}\right.$ osmosis) $\left(\mathrm{m}^{3} / \mathrm{h}\right)$ & 24.6 \\
Weight of one element for RO/MD $(\mathrm{kg})$ & 16 \\
volume of one RO/MD element $\left(\mathrm{m}^{3}\right)$ & $1.016 \times 0.0286 \times 0.201$ \\
\hline Weight and volume of MD module has been considered equal to that of the RO reported in [34].
\end{tabular}

Besides the traditional low concentrated solutions, emerging membrane operations have the capability to treat highly concentrated solutions which are beyond the application limit of traditional processes, thus offering the possibility to achieve the values of MI and WI (Waste intensity) which otherwise are not feasible. This aspect has been explained by considering the example of the treatment of produced water by using membrane crystallization. The experimental details of the study have been explained elsewhere [35]. Changes of mass and waste intensities and overall recovery with respect 
to size of membrane $\left(0.2 \mathrm{~m}^{2}\right.$-active surface area) and weight $(0.467 \mathrm{~kg}$-module) were identified (Figure 7). In the beginning of the experiment, water was only considered the product and in the end of the experiment both water and salt were considered. From the time of saturation, $\mathrm{NaCl}$ was being produced at a rate of $0.063 \pm 0.012 \mathrm{~kg} / \mathrm{h}$. MI and WI decreased significantly with increases in water recovery factor from above 35 to below 3 and 2 for MI and WI, respectively. In the carried out experiments a recovery factor of only $37 \%$ was obtained and continued treatment could further improve MI and WI.

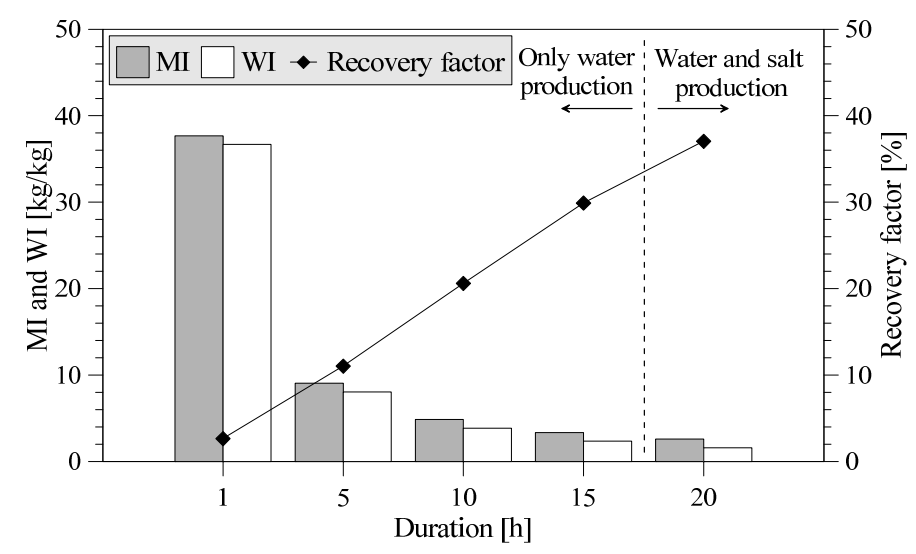

Figure 7. Mass and waste intensities and overall water recovery factor with duration of treatment.

\section{Renewable Energy in Desalination}

Despite rapid increases in membrane based desalination facilities, the use of fossil fuel based energy creates serious concerns regarding the sustainability and cost of obtaining water from desalination. In order to make desalination perfectly aligned with objectives of PIS, the carbon footprint of desalination plants must be reduced. Furthermore, the energy consumption of the process must be lowered to make it affordable for less fortunate communities as well. So far, the largest expansion of desalination facilities has been recorded in energy rich regions and/or regions of the developed world including Spain, Australia, and North America. This is due to the high energy demand of traditional desalination processes. Reverse osmosis is the most economical desalination technology available at a commercial scale at the moment, but still the energy consumption of this technology is more than double the minimum theoretical energy requirements of the process [36]. This scenario has attracted a large interest in the development of desalination based on renewable energy resources.

The cost of renewable desalination is in the same range as that for the traditional resources [37]. The types of renewable energy sources suitable for desalination mainly include solar energy, geothermal energy, and wind energy. The selection of renewable energy sources and applied desalination techniques (RO, thermal, EDs (electrodialysis), etc.) depends upon several factors, mainly including the type of renewable energy sources available in the area, the nature of local water (seawater or brackish water), production capacity, remoteness of the area, etc. [38]. Currently, most of the renewable based desalination facilities are based upon RO and are driven by solar and wind energy [39]. These plants have capacities ranging from a few cubic meters to several hundred cubic meters per day. The specific energy consumption of these units for brackish water ranges from 0.9 to $29.1 \mathrm{kWh} / \mathrm{m}^{3}$ and 2.4 to $17.9 \mathrm{kWh} / \mathrm{m}^{3}$ for brackish and seawater, respectively [40]. Solar and wind energy sources, however, do not allow continuous operation without the use of storage batteries. To overcome this drawback, renewable energy desalination has been integrated with conventional energy sources including grid electricity, diesel generators, etc. The second largest beneficial form of renewable energy based desalination is electrodialysis, which has mainly been operated with wind energy. MD represents 
another emerging player in the field. MD plants driven with solar energy and geothermal energy have been installed in different regions across the globe.

Membrane based renewable desalination is expected to emerge as an interesting sector in the future to reduce carbon emission and desalination costs, particularly in remote regions with abundant sources of saline water and renewable energy but poor infrastructure of electricity. The key factor for further growth of renewable energy desalination is the development and progress in more efficient, cheap renewable energy systems, and improved control and logic systems to regulate the energy output. Moreover, the techno-economic feasibility of membrane based desalination technologies driven with renewable energy sources at large scale needs to be investigated.

\section{Conclusions and Perspectives}

The concept of the process intensification strategy has been significantly implemented in the desalination sector where large, heavy, and energy intensive technologies have been replaced with membrane based technologies with low energy consumption, small footprints, and low environmental consequences. On the basis of process intensification metrics, the membrane operations clearly surpass their conventional thermal counterparts. Relatively less explored membrane based operations including $\mathrm{MD} / \mathrm{MCr}, \mathrm{PRO}, \mathrm{RED}$, etc. are emerging with demonstrated potential to increase water recovery factor, to achieve minerals recovery and renewable energy production, thus breaking the traditional bounds and applications of membrane technology in desalination. Interesting developments of these operations are appearing at commercial scales and mega desalination projects including MEDINA, Seahero, Mega-ton, and the Global MVP project have witnessed the interest of practical applications of these processes. The reshaping of the desalination industry can be foreseen due to the implementation of these processes, and it can be realistically expected that the desalination industry will turn into the energy and raw material sector in the future, with freshwater as a useful byproduct. The promises of new processes, however, are strongly related with successfully overcoming several challenges including the development of better membranes for PRO, RED, and MD/MCr, better control of internal concentration polarization and biofouling, better spacer design, improvement in efficiency of energy recovery devices, improved module design, etc. In remote areas with poor infrastructure, the implementation of renewable energy sources in membrane based desalination is expected to gain more attention. $\mathrm{MD}$ is expected to emerge as a strong contester of $\mathrm{RO}$ in this field, particularly in the regions with abundant sources of solar and geothermal energy.

Author Contributions: Aamer Ali performed the simulation analysis and wrote the manuscript. Francesca Macedonio supervised the work and revised the manuscript. Enrico Drioli initiated the work.

Conflicts of Interest: The authors declare no conflict of interest.

\section{Abbreviations}

The following symbols are used in this manuscript:

$\begin{array}{ll}\text { Configuration 1 } & \text { RO alone } \\ \text { Configuration 2 } & \text { NF-RO } \\ \text { Configuration 3 } & \text { MF-NF-RO } \\ \text { Configuration 4 } & \text { MF-NF(-MCr)-RO } \\ \text { Configuration 5 } & \text { MF-NF-RO(-MCr) } \\ \text { Configuration 6 } & \text { MF-NF(-MCr)-RO(-MD) } \\ \text { Configuration 7 } & \text { MF-NF(-MCr)-RO(-MCr) } \\ \text { DCMD } & \text { Direct contact membrane distillation } \\ \text { ED } & \text { Electrodialysis } \\ \text { ER } & \text { Mechanical energy recovery } \\ \text { FO } & \text { Forward osmosis } \\ \text { IEMs } & \text { Ion exchange membranes } \\ \text { MCr } & \text { Membrane crystallization }\end{array}$




$\begin{array}{ll}\text { MD } & \text { Membrane distillation } \\ \text { MD-RED } & \text { Membrane distillation-reverse electrodialysis } \\ \text { MI } & \text { Mass intensity } \\ \text { MEDINA } & \text { Membrane Based Desalination: An Integrated Approach } \\ \text { MF } & \text { Microfiltration } \\ \text { MSF } & \text { Multi-stage flash } \\ \text { NF } & \text { Nanofiltration } \\ \text { PIS } & \text { Process intensification strategy } \\ \text { PS } & \text { Productivity/size ratio } \\ \text { PW } & \text { Productivity/weight ratio } \\ \text { PRO } & \text { Pressure retarded osmosis } \\ \text { RO } & \text { Reverse osmosis } \\ \text { RED } & \text { Reverse electrodialysis } \\ \text { TE } & \text { Thermal energy recovery } \\ \text { WI } & \text { Waste intensity }\end{array}$

\section{References}

1. Randers, J. 2052: A Global Forecast for the Next Forty Years. Available online: http://www.2052.info/ (accessed on 8 October 2016).

2. UN. Coping with Water Scarcity-Challenge of the Twenty-First Century. Available online: http://www. unwater.org/wwd07/downloads/documents/escarcity.pdf (accessed on 15 October 2016).

3. Stankiewicz, A.I.; Moulijn, J.A. Process Intensification: Transforming Chemical Engineering. Chem. Eng. Prog. 2000, 96, 22-34. [CrossRef]

4. Stankiewicz, A. Reactive separations for process intensification: An industrial perspective. Chem. Eng. Process. 2003, 42, 137-144. [CrossRef]

5. Drioli, E.; Brunetti, A.; di Profio, G.; Barbieri, G. Process intensi Fi cation strategies and membrane engineering. Green Chem. 2012, 14, 1561-1572. [CrossRef]

6. Drioli, E.; Giorno, L. (Eds.) Comprehensive Membrane Science and Engineering; Elsevier B.V.: Amsterdam, The Netherlands, 2010.

7. Charpentier, J.-C. Among the trends for a modern chemical engineering, the third paradigm: The time and length multiscale approach as an efficient tool for process intensification and product design and engineering. Chem. Eng. Res. Des. 2010, 88, 248-254. [CrossRef]

8. Drioli, E.; Stankiewicz, A.I.; Macedonio, F. Membrane engineering in process intensification-An overview. J. Membr. Sci. 2011, 380, 1-8. [CrossRef]

9. Macedonio, F.; Drioli, E.; Gusev, A.A.; Bardow, A.; Semiat, R.; Kurihara, M. Efficient technologies for worldwide clean water supply. Chem. Eng. Process. Process Intensif. 2012, 51, 2-17. [CrossRef]

10. Global Water Intelligence. IDA Desalination Yearbook 2016-2017; Media Analytics, Ltd.: Oxford, UK, 2016.

11. Zhu, A.; Christofides, P.D.; Cohen, Y. Effect of Thermodynamic Restriction on Energy Cost Optimization of RO Membrane Water Desalination. Ind. Eng. Chem. Res. 2009, 48, 6010-6021. [CrossRef]

12. Zhu, A.; Christofides, P.D.; Cohen, Y. On RO membrane and energy costs and associated incentives for future enhancements of membrane permeability. J. Membr. Sci. 2009, 344, 1-5. [CrossRef]

13. Zhu, A.; Christofides, P.D.; Cohen, Y. Energy Consumption Optimization of Reverse Osmosis Membrane Water Desalination Subject to Feed Salinity Fluctuation. Ind. Eng. Chem. Res. 2009, 48, 9581-9589. [CrossRef]

14. Qi, W.; Liu, J.; Christofides, P.D. Supervisory Predictive Control for Long-Term Scheduling of an Integrated Wind/Solar Energy Generation and Water Desalination System. IEEE Trans. Control Syst. Technol. 2012, 20, 504-512. [CrossRef]

15. Criscuoli, A.; Drioli, E. New Metrics for Evaluating the Performance of Membrane Operations in the Logic of Process Intensification. Ind. Eng. Chem. Res. 2007, 46, 2268-2271. [CrossRef]

16. Quist-Jensen, C.A.; Macedonio, F.; Drioli, E. Membrane crystallization for salts recovery from brine-An experimental and theoretical analysis. Desalin. Water Treat. 2015, 3994, 1-11. [CrossRef]

17. Drioli, E.; Criscuoli, A.; Curcio, E. Integrated membrane operations for seawater desalination. Desalination 2002, 147, 77-81. [CrossRef] 
18. Drioli, E.; Curcio, E.; Criscuoli, A.; di Profio, G. Integrated system for recovery of $\mathrm{CaCO}_{3}, \mathrm{NaCl}_{\text {and }}$ $\mathrm{MgSO}_{4} \cdot 7 \mathrm{H}_{2} \mathrm{O}$ from nanofiltration retentate. J. Membr. Sci. 2004, 239, 27-38. [CrossRef]

19. Di Profio, G.; Tucci, S.; Curcio, E.; Drioli, E. Selective Glycine Polymorph Crystallization by Using Microporous Membranes. Cryst. Growth Des. 2007, 7, 526-530. [CrossRef]

20. Quist-jensen, C.A.; Ali, A.; Mondal, S.; Macedonio, F.; Drioli, E. A study of membrane distillation and crystallization for lithium recovery from high-concentrated aqueous solutions. J. Membr. Sci. 2016, 505, 167-173. [CrossRef]

21. Drioli, E.; Criscuoli, A.; Macedonio, F. (Eds.) Membrane Based Desalination: An Integrated Approach (Medina) (European Water Research); IWA Publishing: London, UK, 2011.

22. Macedonio, F.; di Profio, G.; Curcio, E.; Drioli, E. Integrated membrane systems for seawater desalination. Desalination 2006, 200, 612-614. [CrossRef]

23. Drioli, E.; Curcio, E.; di Profio, G.; Macedonio, F.; Criscuoli, A. Integrating Membrane Contactors Technology and Pressure-Driven Membrane Operations for Seawater Desalination. Chem. Eng. Res. Des. 2006, 84, 209-220. [CrossRef]

24. Macedonio, F.; Curcio, E.; Drioli, E. Integrated membrane systems for seawater desalination: Energetic and exergetic analysis, economic evaluation, experimental study. Desalination 2007, 203, 260-276. [CrossRef]

25. Post, J.W.; Goeting, C.H.; Valk, J.; Goinga, S.; Veerman, J.; Hamelers, H.V.M.; Hack, P.J.F.M. Towards implementation of reverse electrodialysis for power generation from salinity gradients. Desalin. Water Treat. 2010, 16, 182-193. [CrossRef]

26. Ashu, R.; Curcio, E.; Brauns, E.; van Baak, W.; Fontananova, E.; Di, G. Membrane Distillation and Reverse Electrodialysis for Near-Zero Liquid Discharge and low energy seawater desalination. J. Membr. Sci. 2015, 496, 325-333.

27. Wang, X.; Huang, Z.; Li, L.; Huang, S.; Hao, E.; Scott, K. Energy Generation from Osmotic Pressure Difference Between the Low and High Salinity Water by Pressure Retarded Osmosis. J. Technol. Innov. Renew. Energy 2012, 1, 122-130. [CrossRef]

28. Klaysom, C.; Cath, T.Y.; Depuydt, T.; Vankelecom, I.F.J. Forward and pressure retarded osmosis: Potential solutions for global challenges in energy and water supply. Chem. Soc. Rev. 2013, 42, 6959-6989. [CrossRef] [PubMed]

29. O'Toole, G.; Jones, L.; Coutinho, C.; Hayes, C.; Napoles, M.; Achilli, A. River-to-sea pressure retarded osmosis: Resource utilization in a full-scale facility. Desalination 2016, 389, 39-51. [CrossRef]

30. Han, G.; Zuo, J.; Wan, C.; Chung, T. Hybrid pressure retarded osmosis-Membrane distillation (PRO-MD) process for osmotic power and clean water generation. Environ. Sci. Water Res. Technol. 2015, 1, 507-515. [CrossRef]

31. Achilli, A.; Prante, J.L.; Hancock, N.T.; Maxwell, E.B.; Childress, A.E. Experimental Results from RO-PRO: A Next Generation System for Low-Energy Desalination. Environ. Sci. Technol. 2014, 48, 6437-6443. [CrossRef] [PubMed]

32. Global MVP 2013-2018. Available online: http://globalmvp.org/english/ (accessed on 16 October 2016).

33. El-Dessouky, H.T.; Ettouney, H.M. Fundamentals of Salt Water Desalination; Elsevier B.V.: Amsterdam, The Netherlands, 2002; pp. 271-407.

34. GE Water \& Process Technologies, AD HR Series, Seawater RO High Rejection Elements. Available online: http://www.lenntech.com/Data-sheet/GE-Osmonics-AD-HR-series-Sea-Water-ROHigh-Rejection-Desalination.pdf (accessed on 27 Otober, 2016).

35. Ali, A.; Quist-jensen, C.A.; Macedonio, F.; Drioli, E. Application of Membrane Crystallization for Minerals' Recovery from Produced Water. Membranes 2015, 5, 772-792. [CrossRef] [PubMed]

36. Khayet, M. Solar desalination by membrane distillation: Dispersion in energy consumption analysis and water production costs (A review). Desalination 2013, 308, 89-101. [CrossRef]

37. Gnaneswar, V.; Nirmalakhandan, N.; Deng, S. Renewable and sustainable approaches for desalination. Renew. Sustain. Energy Rev. 2010, 14, 2641-2654.

38. Eltawil, M.A.; Zhengming, Z.; Yuan, L. Renewable energy powered desalination systems: Technologies and economics-state of the art. In Proceedings of the 12th International Water Technology Conference, Alexandria, Egypt, 27-30 March 2008; pp. 1-38. 
39. Tzen, E.; Morris, R. Renewable energy sources for desalination. Sol. Energy 2003, 75, 375-379. [CrossRef]

40. Ghermandi, A.; Messalem, R. Solar-driven desalination with reverse osmosis: The state of the art. Desalin. Water Treat. 2009, 7, 285-296. [CrossRef] 